\title{
UK research
}

\section{Review of research by numbers}

THE Prime Minister, Mrs Margaret Thatcher, announced in the House of Commons last week the publication of the first of a series of annual reviews of government-supported research and development. The need for such a review was argued in 1981 by the House of Lords Select Committee on Science and Technology, which doubted the ability of the Treasury adequately to judge individual departments' research programmes against their responsibilities.

The science and technology secretariat at the Cabinet Office has carried out the first review which enables some trends to be discerned. As a public document, the review is ostentatiously laconic, replete with figures showing the sums of money spent by various government departments (which are listed consecutively) but entirely free from value judgements.

Nevertheless, the review touches base with most of the issues now causing anxiety within the British system of research and higher education. It refers to the dualsupport system (but does not say whether it has broken down), mentions the problems encountered by the research councils in paying overseas subscriptions (but recommending no specific remedies), and so on.

It is not immediately apparent whether this is the kind of document for which the House of Lords was asking two years ago, although the political problems that would arise if the Cabinet Office were seen publicly to have a view on how government departments conduct their affairs are readily appreciated.

In one respect, however, the review does break new ground in Britain by adopting as the basis for its calculations a set of definitions of basic research, applied research and development which were first promulgated by the Organization for Economic Cooperation and Development (OECD) in its "Frascati Manual".

Evidently the Cabinet Office intends to apply these definitions to the classification of British research and development, raising in the process questions such as whether the collection of data as part of some routine operation, or the application of known knowledge to concrete tasks, should be classified as research.

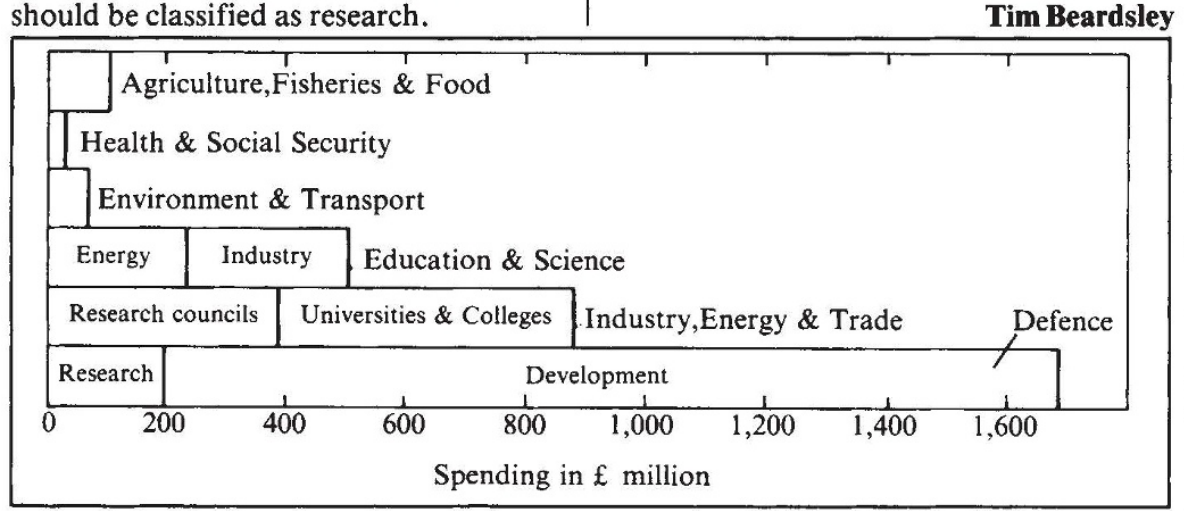

the most recent records are for 1981-82, defence spending shows the biggest increase between $1973 / 74$ and $1981 / 82$ while the proportion of all governmentsupported research and development by the Trade and Industry and Energy departments fell from 21.5 to 15.4 per cent over the same period. Expenditure by the Department of Education and Science shows a modest increase, from 24.6 to 27.4 per cent of the total.

The decrease in the figures for the Department of Trade and Industry is attributed to the running down of the programmes of support for the RB-211 aeroengine and Concorde civil aircraft. The large figure for defence includes the cost of development of specific items of equipment.

- The increase in the share of the Department of Education and Science is a sur. prise. At a meeting in London last week, Dr John Burnett, Principal of the University of Edinburgh, argued that in the university sector, forward commitments on research equipment now exceed the ability of the system to pay for them. But the steep drop of support from the University Grants Committee in 1981 was preceded by a period of declining support for equipment and consumables, according to Sir David Philips, chairman of the Advisory Board for the Research Councils. And Professor John Kingman, chairman of the Science and Engineering Research Council, said that the diminished ability of his council to accede to all first-rate project grant applications was in part a consequence of the increasing sophistication of equipment but that government support for particular initiatives, such as that in information technology, had come out of the science budget. Not every body agrees that academic research is being hurt however. Drs Ben Martin and John Irvine of the Science Policy Research Unit at the University of Sussex argued that the evidence for a decline is largely anecdotal, and advocated a new approach to monitoring research output: the peer-review system, they said, might not be an adequate way of making decisions about closures.

Tim Beardsley
Information technology Europlan
in doldrums

wis hold. According to $\mathrm{Mr}$ Brian Oakley, director of the Alvey programme, Britain, with by far the fastest-growing population of microcomputers in Europe, is faced with "an incredible opportunity". This may be for the wrong reasons - people are playing "Pac-man" and "Space Invaders" rather than writing programs. But Oakley believes there is no smoke without fire.

Oakley is also proud of his team in the directorate, most of them on secondement from industry and still paid by their original employers. This arrangment has 
caused some companies to fear loss of confidentiality, but those have been overcome, Oakley says. Even so, after Oakley's many years in government, he can say "I have never been in such a position where I can find out so rapidly exactly what companies think". With his $£ 500$ million, this gives Oakley a position of power and pulsetaking that Davignon or his staff would clearly like to exercise on the European scale.

There is some evidence that West Germany may follow the British lead. A plan for information technology is said to be in gestation - it will probably go to the German parliament in March, after the 28 February deadline Davignon seeks for agreement on Esprit. The upshot, that the two main complainants over the EEC budget may have made their own arrangements by them, does not augre well for Esprit.

Robert Walgate

\section{East German chemicals}

\section{Back to coal}

EAST Germany is planning a return to coal and, in particular, to domestically available lignite as the basis of its chemical industry, according to a report from the German Institute for Economic Research in West Berlin. Carbon chemistry has declined in importance in East Germany since 1975, with oil being used as the primary chemical feedstock.

Last November, at a meeting of the Central Committee of the United Socialist Party (SED), party leader Erich Honecker stressed that he attached the "greatest importance" to coal gasification and liquefaction. Current plans call for 80 per cent of the growth in lignite production to be allotted as a feedstock for the chemical industry. Expansion of coal tar and, above all, carbide production is a prime objective.

According to $\mathrm{Mr}$ Honecker, processing chemistry - including coal and lignite ranks with biotechnology and microelectronics among the sciences which must "increasingly permeate" the East German economy. The target date for the largescale liquefaction of lignite is, at the latest, 1992 , with a planned annual processing of 10 million tonnes of lignite into fuel and liquid feedstocks. A team of 150 scientists at the carbo-chemical centre in Boehlen is said to be working on new sophisticated processes for lignite gasification and processing.

At present, however, the return to coal and acetylene seems to be based on a revival of old methods and technologies. This, according to the German Institute for Economic Research, involves a considerable loss of labour productivity and an increase in energy consumption, since in existing plants, nine to ten tonnes of raw lignite and a "very high input" of hydrogen are needed to replace one tonne of oil.

Vera Rich
US-Soviet space research Moves for joint programme

Moscow radio's English-language service Americans.

for North America has dropped several hints during the past few weeks suggesting a Soviet willingness to resume joint research projects in space. Such cooperation has, in fact, never entirely stopped. There is still some joint work on space medicine - including animal experiments on calcium loss due to weightlessness and Soviet-American meetings of planetologists involved in Venus studies.

The recent hints suggest, however, that the Soviet side would like to see a resumption of plans for a joint manned mission. One commentator noted that there was at one time a plan for a link-up between the US space shuttle and a Soviet Salyut station. This, he claimed, was "unilaterally suspended" by the American administration, which has "increasingly been expanding military space projects at the expense of scientific research in space".

The same attitude of blaming the Americans for the cessation of these plans was adopted by Vladislav Dobrosel'skii, head of the external relations administration of the Soviet Academy of Sciences. He maintained that, in spite of highlypublicized official embargoes, the Washington government has quietly maintained a policy of preserving exchanges and contacts in areas where the Soviet Union is undoubtedly ahead. In the field of space medicine and biology, in which Soviet achievements are "obvious", the Soviet Union had however been guided by "humanitarian motives" in making their experience and knowhow available to the
Ostensibly, Dobrosel'skii's call was for a restoration of "broad scientific ties" between the United States and the Soviet Union. His stress on the Soviet lead position in space, and the advantages which, even now, the Americans receive from it, suggests that renewed cooperation in space was the prime purpose of the broadcast.

What political ambience the Soviet Union would demand as a prerequisite for a major joint space experiment has not, so far, been spelled out. (So far the commentators have simply urged that such cooperation would be conducive to peace and detente.) Dobrosel'skii himself urged that cooperation should be "on a footing of equality, without any discrimination" and "free of contingency fluctuations" (presumably of political origin). It is possible, therefore, that the suggestions were intended as a warm-up to the latest round of "confidence building" negotiations which opened in Stockholm last week.

It should be remembered, however, that in 1982, a Moscow radio commentator hinted that the United Kingdom could qualify, like France and India, for participation in the manned "Interkosmos" programme - provided it first rejected the siting of US missiles on its soil.

If the possibility of a joint United StatesSoviet major space effort goes further than the recent preliminary kite-flying, it seems highly likely that some concession on arms limitation will be demanded by the Soviet side as a prerequisite to participation.

Vera Rich

\section{UK observatories reprieved}

GROUND-based astronomers in Britain and particularly those at the Royal Greenwich Observatory (RGO) should be breathing a sigh of relief this week. The Willmore panel set up to advise the Science and Engineering Research Council (SERC) on the future of the British observatories has recommended that RGO, the Royal Observatory Edinburgh (ROE) and Rutherford Appleton Laboratory (RAL) should all continue to be supported by the SERC. This recommendation has been accepted by the body directly responsible for UK astronomy, SERC's Astronomy Space and Radio (ASR) Board, thus stilling fears that RGO might be abolished in the near future (see Nature 301, 102; 1983).

The final decision, morever, rests with the council, due to meet in mid-February, although there is no reason to believe that it will not follow the recommendation. But the observatories will probably not escape totally unscathed, for the plans now laid for instrumentation of the new telescopes at La Palma and Hawaii will probably be cut back, or be streched out. Those working at RGO, who have been expecting to co-ordinate the remote operation by satellite of the La Palma telescopes, will for example be displeased by the news that the initial demonstration of this technique, both for La Palma and for the millimetrewave telescope being constructed in Hawaii, will be carried out at the Edinburgh Observatory.

While these decisions relate to the longterm future of the ASR Board's activities, immediate problems remain. Deficits arising from the effects of exchange rate fluctuations on international subscriptions have been partly compensated for by the Treasury, to the tune of $£ 7$ million. But for the financial year 1984-85, the board still has to cut about $£ 2$ million from its original estimate. To achieve this, the board intends to cut funds from research grants by 5 per cent, RGO and RAL manpower by about 10 per cent and 15 per cent respectively and other institutional costs by about 10 per cent.
Philip Campbell 